\title{
UM NOVO VIAJANTE NA LITERATURA DE VIAGEM
}

Günther Augustin *

\begin{abstract}
Resumo: A literatura de viagem textualiza a travessia das fronteiras, tanto geográficas quanto interculturais e interdisciplinares. Ela representa olhares diferentes, distanciados que alimentam a memória e o imaginário culturais. $O$ mais recente candidato para ingressar no cânone dessa literatura é W. L. v. Eschwege. A leitura aqui apresentada dos seus textos focaliza os aspectos interdisciplinar, intercultural e intersticial do seu olhar que é um olhar europeu em trânsito e em transição. $O$ discurso pós-colonial questiona esse olhar e suas implicações epistemológicas. A dialética entre olhar estrangeiro e olhar de si está em jogo.
\end{abstract}

Palavras-chave: literatura de viagem; intercultural; olhar europeu; discurso; Eschwege

\section{Introdução}

Apenas recentemente foram publicadas edições brasileiras completas das duas obras do viajante Wilhelm Ludwig von Eschwege que são as mais importantes dele em termos de literatura de viagem. Brasil, novo mundo, publicado em 1996 (vol. I) e 2000 (vol. II), e Jornal do Brasil, em 2002. Portanto, somente agora, quase dois séculos após o previsto (AUGUSTIN, 2003, p. 89) o público brasileiro pode verificar o que esse viajante escreveu sobre o Brasil.

Depois servir quase uma década como funcionário da coroa portuguesa em Portugal, Eschwege veio em 1811 para mapear Minas Gerais com suas riquezas. Cumpriu a ordem, entregou o primeiro mapa moderno ao rei, no Rio de Janeiro. O documento original seguiu para Londres para a confecção definitiva, mas nunca saiu do papel. Talvez, quem sabe, o rei, em trânsito na colônia, colonizador e colonizado ao mesmo tempo, não gostou de um detalhe: o mapeador resolveu adotar o primeiro meridiano tendo como referência o Rio de Janeiro. A visão da capital brasileira como centro do mundo poderia desestabilizar a ordem mundial vigente.

Como funcionário contratado pelo Coroa portuguesa, atuou durante a segunda década do século XIX, principalmente em Minas Gerais. Eschwege retrata um Brasil em transição, preindependência, sob o governo de João VI. Foi o principal informante do público alemã, inclusive Goethe, que gostou das conversas com o viajante sobre sua coleção de pedras minerais. Seu olhar crítico levou a juízos, às vezes, arrogantes eurocentristas e desconcertantes para o público brasileiro. Ao mesmo tempo, seus textos

\footnotetext{
Doutor em Estudos Literários. Professor Adjunto Faculdade de Letras da Universidade Federal de Minas Gerais (UFMG).
} 
expressam compreensão e simpatia para com o Brasil como país emergente. Como viajante intercultural, Eschwege atravessou fronteiras geográficas, nacionais, sociais, históricas e culturais, deslocando-se para outros locais, estados, países, passando por épocas históricas, regimes políticos e econômicos, mentalidades e domínios lingüísticos diferentes. Eschwege e seus textos têm algo de híbrido, fugindo em alguns aspectos dos esquemas preestabelecidos pelas análises sumárias dos relatos de viagem que compõem a literatura dos viajantes. Focalizando no caráter fronteiriço das atuações de Eschwege propõe-se estudar o olhar de Eschwege, transcrito nos seus textos, a partir de uma ótica da estrangeiridade e do "in-between", termo usado por Bhabha. Bhabha cita Heidegger para destacar este aspecto: "Sempre, e sempre de modo diferente, a ponte acompanha os caminhos morosos ou pressados dos homens para lá e para cá, de modo que eles possam alcançar outras margens. A ponte reúne enquanto passagem que atravessa." (BHABHA, 1998, p. 24)

Quando mapeamos os textos do viajante, analisamos sua discursividade e identificamos uma diversidade de discursos como textualização do olhar de múltiplas perspectivas do viajante que percebe a topografia transformando a em tropografia. $\mathrm{O}$ ouro preto torna-se paradoxo de riqueza pobre. $\mathrm{O}$ conhecimento produzido pelo viajante escritor pode ser lido como conhecimento literário do mundo. O relato de trabalho de campo do geólogo transforma-se em etnografia e as vezes em poesia, primeiro sobre o outro, depois sobre si, quando a jornada de trabalho se confunde com jornada sentimental. Lemos os textos menos como documentos e mais como monumentos culturais. Além de culturais, são interculturais: o viajante, seu olhar e sua linguagem migram, atravessam fronteiras, se transformam. O observador vira escritor e se inscreve na sua escrita, primeiro ainda tímida, e depois ganhando coragem, a escrita fica mais rica.. Os leitores, primeiro no velho continente, se confrontam com um outro mundo, e nas traduções, no Brasil, com um outro seu.

Depois de considerações teóricas referente à literaricidade e a discursividade, mostramos o escritor na prática. Em seguida, em quatro textualizações do olhar viajante, focalizamos nos discursos articulados e na interdiscursividade dos textos como literatura de viagem. Finalizamos com a conclusão sobre os textos de Eschwege e reflexões sobre as implicações decorrentes da sua leitura no Brasil.

\section{O conhecimento literário do mundo}

Enquanto os relatos de viagem muitas vezes servem como fonte de informações, procuramos neles também o literário no sentido literal e metonímico. Como literatura de viagem, esses textos são paradigmáticos para o que Bento Prado Jr. chama, "na falta de melhor expressão, de conhecimento literário do mundo". (PRADO Jr., 2004, p.12) O olhar do viajante e o do poeta se encontram no texto. Utilizando uma conceituação da época dos nossos viajantes, diríamos que o viajante textualiza seu olhar externo dos fenômenos enquanto o poeta, o interno. O texto resultante é sempre tanto pensamento quanto poesia, o que, para Kant, são quase sinônimo. Entendemos o discurso literário como interdiscurso cultural onde discursos especializados cruzam o texto. Lemos os textos como discurso composto de uma multiplicidade de discursos, entendendo discurso como fala ou escrita perspectivista e 
interessada. Analisamos a discursividade dos textos, procurando identificar as perspectivas e os interesses das vozes que se articulam no discurso, possibilitando assim uma leitura crítica.

A leitura da literatura como interdiscurso visa os textos como espaços de reintegração dos conhecimentos normalmente organizados em discursos especializados, definindo literaricidade como interação entre estruturas semióticas (imanentes) e fatores discursivos (externos) (LINK; PARR, 1988, p.108). Nessa perspectiva interdiscursiva, a literatura dos viajantes encontra seu lugar, onde se mistura uma multiplicidade de discursos. Literatura seria de um lado discurso específico, de outro um discurso que recorre a elementos supradiscursivos em dois aspectos: de forma extensiva, pela acumulação enciclopédica de conhecimentos, e de forma intensiva, pela utilização de material polissêmico de tal maneira que aumenta sua ambivalência e extensibilidade semântica. A análise literária focaliza a tropologia da linguagem; a análise da discursividade focaliza a perspectividade do olhar e sua textualização. Ambos não são bem separáveis; trata-se de "unstable ground".( SPURR, 1993. p. 2)

\section{Olhar estrangeiro, perspectivista e intercultural:}

No seu Livros de Viagem Miriam L. M. Leite se orienta em Simmel que destacou o aspecto fundamental do olhar distanciado, refratado, "fora do lugar" do viajante estrangeiro. "Viajantes e estrangeiros, embora sem ser propriamente nômades, se fixam apenas temporariamente, conservando uma posição de autonomia diante do espaço ocupado pela população local (Simmel, 1939, pp. 273-295).” (LEITE, 1997, p. 160)

Visto dessa forma, o viajante estrangeiro traz uma percepção de fora, um olhar objetivo, ideal da visão científica de acordo com idéias científicas de coerência, consistência e conseqüência analítica. Mas "se de um lado sua percepção estava aguçada pelas possibilidades de comparações culturais, não deixava de ser prejudicada pela falta de vivência do habitante, pois desconhecia a história do presente testemunho." (LEITE, 1997, p. 163). Assim o olhar objetivo, científico do viajante estrangeiro traz consigo a sua história e tudo que ela implica em termos de bagagem cultural européia. A diferença das histórias pode resultar em diferentes narrativas. Se o olhar do viajante estrangeiro vem de uma tradição iluminista, ele carrega em sua bagagem epistemológica o episteme iluminista tão questionado pela crítica desconstrutivista assimilada pela teoria pós-colonial. No jogo da alteridade precisa-se distanciar do olhar distanciado dos viajantes. Moreiras, por exemplo, observa a respeito do olhar latino-americanista que a posição metropolitana/metropolitanista de enunciação não pode ser tratado como certa ou aceita como a priori natural e inquestionável da produção de conhecimento. A dissociação estrutural dentro do próprio latino-americanismo, como estágio complexo na negociação da alteridade social-epistêmica passou para o centro das preocupações disciplinares. (MOREIRAS, 2001. p. 161).

Partimos da hipótese de que, nos textos de Eschwege, textualiza-se um olhar perspectivista europeu no encontro com uma outra natureza, outra terra e outros homens, isto é, uma outra cultura. $\mathrm{Na}$ textualização desse encontro intercultural articulam-se discursos que contribuíram para o imaginário brasileiro: paraíso terrestre, democracia 
racial, gigante adormecido e país tropicalista, além de conterem elementos de um discurso colonial como concebido por M. L. Pratt, H. Bhabha e E. Said, para citar apenas alguns dos mais conhecidos.

O estudo dos relatos dos viajantes permite avaliar se seu conhecimento alimentou o imaginário brasileiro do mito fundador, da visão do paraíso, da natureza pura tropical ou até que ponto seus olhares contribuíram para diferenciar uma imagem estereotipada e dicotomizada. J. C. Reis pergunta e responde: "Seria possível produzir um discurso sobre o Brasil desapaixonado, científico, verdadeiro? Dificilmente. É por isso que todas as representações do Brasil são relevantes, pois, juntas, revelam uma idéia do Brasil complexa...”. (REIS, 2000a, p. 45-46). Gilberto Freire constatou que o imaginário brasileiro se alimentou mais de fora para dentro. Do ponto de vista do discurso pós-colonial, que questiona essa perspectiva metropolitanista eurocentrista, o conhecimento dos textos que constituíram o imaginário permite avaliar o valor desses textos como imaginário hegemônico ou próprio sobre si, sua leitura como encontro imperial ou intercultural.

\section{Escrita como afirmação cultural}

Têm evidencias que Eschwege sofreu de um complexo de inferioridade como cientista e escritor. Logo no início do Pluto Brasiliensis, Eschwege depara com a dificuldade de separar textualmente acontecimentos relacionados intimamente uns com os outros já que, na narrativa, a simultaneidade tem que ser seqüencializada. "Só uma pena hábil, melhor portanto que a minha, poderia tornar interessante a dissecação histórica de matéria tão curiosa quanto instrutiva. Na falta de outros recursos, limitar-me-ei à descrição dos fatos." (ESCHWEGE, 1979, p. 23) Pode-se supor ainda que Eschwege tivesse uma motivação pessoal específica. Saiu da sua pátria para conhecer o mundo, mas também para compensar a amargura da rejeição por parte da família da sua (ex-)namorada Sofia. A publicação de uma obra sobre o Brasil se tornou um ato de afirmação pessoal. Não foi por acaso que o Journal von Brasilien foi publicado em Weimar, onde Goethe atuou como ministro, e Sofia como governanta na corte do príncipe. No prefácio ao segundo volume desse relato, Eschwege já não hesita mais em falar de seus "trabalhos literários" e faz um grande esforço para justificar essa qualificação.

A escrita parece também cumprir um papel de afirmação cultural, uma confirmação do dom de cultura como capacidade de escrever e pensar. Na primeira frase das suas notícias sobre os selvagens do Brasil, Eschwege afirma: 'O ser humano, no estado natural cru, desperta para o homem pensante sempre interesse especial.' (ESCHWEGE, 1827, p. 214) ${ }^{1}$ No segundo capítulo do Jornal do Brasil, portanto bem no início da sua obra, trata por extenso dos povos selvagens do Brasil. Na parte "O interior das casas e seu modo de viver", observa: "Falam pouco uns com os outros, e suas conversas são monossilábicas e pausadas. Calados, soltam suas baforadas e parecem estar pensando profundamente. Mas, uma vez que não têm resultados visíveis desse pensamento, é bem possível que não pensem nada". (ESCHWEGE, 2002, p. 107)

\footnotetext{
1 Citações em aspas simples referem-se ao original alemão, traduzidas aqui pelo autor.
} 
se abrem:

Como na escrita, ocorre uma transformação do olhar também quando novas vistas Atravessando a serra, chega-se a um mundo novo: depois de mais de 50 léguas de
estrada mata adentro com uma vista muito limitada, descortinam-se diante dos
olhos um horizonte aberto e pradarias. A floresta desaparece pouco a pouco pelos
lados e surgem cumes pelados, até onde os olhos alcançam, o que chamam de
campos, aos quais já fiz referência no primeiro volume" (ESCHWEGE, 2002, p.
247)

Eschwege se refere à sua explicação de "Campos" no início do Jornal do Brasil, a sua primeira nota explicativa. Ainda entra uma referência à Europa, mas ela não se faz à paisagem, mas às casas: “...junto às casas havia lindas plantações, cereais crescendo com um vigor como só é visto na Europa" (ESCHWEGE, 2002, p. 247). O tropo não é mais o da negação mas sim um paradoxo involuntário: ver alguma coisa aqui "só visto na Europa".

\section{Tradução intercultural}

Nota-se nos textos de Eschwege uma constante preocupação com a denominação das coisas. Marcado por uma época que viu a transparência entre as coisas e as palavras, isto é, a referência, se ofuscar, ele que sempre parte dos fenômenos visíveis, daqueles dados pelos sentidos, deixa transparecer uma ansiedade por manter essa relação. Formulações como "se me permitem assim dizer" aparecem em vários momentos nos seus relatos. Pelo menos três fatores são evidentes nessa constelação: a história natural classificou, Kant mostrou as implicações transcendentais da classificação e Eschwege demonstra consciência dessas implicações, enquanto alega sua incompetência literária. Não era uma posição cômoda para descrever as coisas em sua ordem na época. Foucault forneceu a análise clássica do pensamento do século XVIII, em As coisas e as palavras. A ordenação tabelária consegue subsumir a multiplicidade dos fenômenos em uma seqüência descritiva e no campo de uma matéria que seria uma ciência geral da ordem das coisas, procurando a proximidade entre coisas e palavras.

Eschwege parece estar preocupado em manter a mínima distância possível entre as coisas e as palavras e pratica uma espécie de tradução cultural. Explica uma série de palavras porque as acha intraduzíveis ou acha melhor garantir seu significado pela sua manutenção em português. No início, parece que explica apenas termos técnicos de mineração. Mas se olharmos a lista, ela representa um verdadeiro espelho de especificidade cultural, a partir de uma visão intercultural que destaca o outro, o diferente do próprio, culturalmente falando: garimpeiro, mineiro, roceiro, vadio, Guarda-Mor, Juiz de Fora, Veranico, farinha, morro, campos, sertões, rancho, venda, arraial etc. Quem entende o significado dessas palavras já tem uma noção do Brasil da época. Além de dar explicações de palavras que julgou intraduzíveis, também integrou muitas outras em português no seu texto alemão, criando assim elementos de uma espécie de interlinguagem ao longo dos seus relatos, estendendo as fronteiras da sua língua pela incorporação de novos signos de uma outra cultura. 
Embora o conceito de tradução cultural utilizado nesta tese não seja derivado de $\mathrm{H}$. K. Bhabha, pensamos que o estudioso articula alguns aspectos que constituem a problemática e a necessidade do que podemos chamar tradução cultural. Assim se dá com a "experiência migrante, transcultural", as "fronteiras" e o "intraduzível" - em vez de se chegar a nomes pré-fabricados. Bhabha sugere uma dialética da negação cultural como negociação, uma cisão por meio da agência da estrangeiridade, e cita R. Pannwitz com seu propósito de não transformar o hindi, o grego, o inglês em alemão, [mas], ao contrário, transformar o alemão em hindi, grego, inglês." (BHABHA, 1998, p. 312) Com sua incorporação de palavras, conceitos e pequenas frases em português no seu texto alemão, Eschwege praticou um pouco desse propósito: o que teria sido alemão foi levado para o português em função de sua intraduzibilidade, criando uma "contact-zone" (PRATT, 1992) textual, uma fronteira trans ou intercultural, que seria uma fronteira não de separação mas de aproximação.

\section{O Primeiro dia}

No Jornal do Brasil, o texto inicial dos livros de Eschwege sobre o Brasil é a narrativa de uma viagem de cinco dias, "Viagem à tribo selvagem dos índios coroados". O relato do primeiro dia apresenta de forma compactada uma diversidade de aspectos captados pelo olhar do viajante e textualizados pelo narrador, formando uma rede de significados que constituem elementos básicos dos discursos presentes no texto, identificáveis pela análise da discursividade da narrativa. Nesse texto, que denominamos de o "Primeiro dia", podemos ver, de forma exemplar, como a discursividade se revela em um segundo plano, quando se percebe a formação de uma rede significativa em função da modificação da significação primária: quando, por exemplo, o pão transforma-se do alimento em símbolo, ou o ouro, do metal dourado de riqueza em ouro preto de pobreza, ou a pacificação, em guerra.

O texto do Primeiro dia como um todo apresenta a maior parte dos discursos articulados nos relatos. O enfoque na percepção pelo olhar é destacado pelas palavras "visivelmente", "ver", "verificar" e "vista", indicando o kantianismo do viajante. Nosso modo de percepção nunca é desinteressado. Percebemos as coisas com os sentidos, elas nos aparecem agradáveis ou desagradáveis, belas ou feias. Avistando a cidade de Mariana, confere-se à vista "um aspecto muito simpático" (ESCHWEGE, 2002, p. 54), e o panorama da serra ao sudeste considera schön (bonito, belo) (ESCHWEGE, 1818, p. 39). Mas o que se destaca no texto são as observações científicas. O que percebe "visivelmente" é "conforme as minhas medições barométricas" ou "verificado" de outra maneira (ESCHWEGE, 2002, p. 49). Como cientista, seu olhar é determinado por sua formação acadêmica. Seu olhar abrangente observa a natureza física, principalmente geofísica, e como os homens a transformam e exploram. Seu olhar é voltado para a riqueza e a pobreza, o que existe em excesso e o que falta, e porque isto ocorre.

Na textualização desse olhar podemos identificar, já no Primeiro dia, uma série de tropos que aí se infiltram e tornam característico o discurso de Eschwege. Os campos semânticos de "rico/riqueza" e "pobre/pobreza" dominam boa parte do texto do Primeiro dia, servindo como dispositivos classificatórios tanto da natureza quanto dos homens e seu 
habitat. A tropologia da linguagem faz com que o olhar empírico se textualize como discurso. A discursividade se manifesta na perspectiva do olhar que focaliza a riqueza de uma parte da serra, a do padre explorador, e a pobreza de uma outra parte, a dos pretos e povoados pobres. A perspectiva é crítica e irônica, constatando o paradoxo da pobreza causada pela riqueza em ouro. A "serra rica em ouro" fica incluída na rede de circulação capitalista através da antropomorfização. Ela "deu muitos milhões em dinheiro desde a sua descoberta e exploração. Suas riquezas começam perto de Mariana" (ESCHWEGE, 2002, p. 47). O homem se apropriou dela quando no seu "cume um religioso... se estabeleceu..." (ESCHWEGE, 2002, p. 54). É evidente a analogia entre a hierarquização topográfica, social e até cultural. No fundo do vale trabalham os "negros pobres", expressão polissêmica que os marca como inferiorizados em um duplo sentido. Em três momentos o texto associa os negros a um nível mais baixo, física e socialmente, estabelecendo uma relação entre o ouro e os negros pobres. O primeiro momento é de uma sutileza e ironia provavelmente involuntárias: voltando seu olhar ao seu principal objeto de interesse, a riqueza das serras, detectando camadas ora ferruginosas, ora auríferas, Eschwege explica: “... toda a poeira e toda a sujeira nas estradas são auríferas; sim, até a poeira varrida das casas contém ouro e é aproveitada por um ou outro negro pobre" (ESCHWEGE, 2002, p. 48). O negro é associado ao lixo, o último e mais baixo lugar onde se encontra ouro.

Resumindo a leitura analítica do texto do Primeiro dia, ficou evidente como o viajante, com seu olhar de múltiplas perspectivas, anota na sua jornada uma diversidade de impressões cuja representação textualizada lhe confere sentidos ou não, conforme o(s) modelo(s) de realidade do autor. Ele anota tanto a riqueza quanto a pobreza, a decadência, a perda de recursos, a falta de conhecimentos e de coragem, a exploração da natureza e dos homens, as formações naturais e sociais e, em poucos momentos, as belezas naturais e urbanas. Sua percepção intuitiva transforma-se em texto discursivo utilizando tropos como antropomorfização, metonímia, metáforas, ironia, paradoxo, paralelismos, polissemia, analogia e símbolos, criando uma rede de significações que representam uma visão particular sua das evidências empíricas. A descrição aparentemente desinteressada deixa transparecer comentários, interpretações, interrogações, questionamentos e críticas. O ouro preto não é mais apenas um mineral; transformou-se em metáfora que lembra a extração da riqueza mineral pelos negros pobres. $\mathrm{O}$ mineral se transforma em capital produzindo desigualdades e conflitos que parecem ser quase naturais, sem que ele os naturalize. A interação do homem com a natureza é simultaneamente construtiva e destrutiva, tornando a relação entre homem e natureza também conflituosa. É o ponto de vista múltiplo de Eschwege, vendo o aproveitável e o descartável, o agradável e o desagradável, o belo e o útil. É um olhar mais prático do que estético, selecionando o que interessa à narrativa da produção e do aproveitamento. Sem o homem, a natureza não interessa; pela cultura do homem a natureza se transforma do estado cru em estado enobrecido.

\section{Flüchtiges Naturgemälde}

Como o texto do Primeiro dia, o primeiro texto em Brasilien, die Neue Welt, intitulado "Flüchtiges Naturgemälde" (Quadro de natureza esboçado), é indicativo do 
modo de escrever do viajante no Novo Mundo. Enquanto no Primeiro dia podemos perceber a falta de um programa de escrita, a não ser a necessidade ou obrigação de produzir um relato caminhando, olhando e anotando, o primeiro texto de Brasil, Novo Mundo é um texto bem diferente, bem elaborado. Nele o autor se utiliza da descrição da baía do porto do Rio de Janeiro para indicar alguns parâmetros básicos do seu olhar e de seu modo de escrever. Evidenciam-se como intertextos a Estética Transcendental, de Kant, e Ansichten der Natur, de A. von Humboldt. Deste último consta no título do texto o conceito básico da sua proposta de um estilo estético-científico da literatura de viagem, o Naturgemälde, e no decorrer do texto aparecem as palavras Ansichten der Natur no seu sentido primário, mas ecoando o título programático de Humboldt. Com as referências a Kant e Humboldt, o autor se alinha aos seus discursos; portanto, ao mesmo tempo se diferencia deles, dando a entender que não é Dichter (poeta) e nem Denker (pensador), no sentido filosófico. O viajante admite que as vistas são tão românticas que apenas um poeta poderia descrevê-las já que evocam um sentimento para o qual não há palavras, a não ser a exclamação wie schön! (que belo!), sentimento que, conforme Kant, não é definível com conceitos. O narrador naturalista, passando pela baía do Rio, precisa de conceitos. Pensa sobre o que viu, mas não faz filosofia, apenas reflexões para poder escrever, lembrando-se disso em três momentos. Primeiramente com a imagem do caminhante filosofante (philosophierende Wanderer), que deita no barco em cima do simples leito de junco, quando a escuridão não deixa mais nada para observar. A lua transforma a noite em dia, sem que isso levasse esse viajante a fantasias românticas. Em uma nota observa: "O luar, nos trópicos, é incomparavelmente mais claro que o europeu, permitindo perfeitamente a leitura." (ESCHWEGE, 1996, p. 59)

Nesse Naturgemälde o narrador procura combinar os programas dos dois mestres, do filósofo Kant e do naturalista Alexander von Humboldt, retratando um quadro em movimento através da exemplificação dos dois conceitos a priori, espaço e tempo. Os dois primeiros parágrafos evocam um ar de leveza, tanto do espírito do viajante quanto do movimento da água, muito em contraste com o final do texto, o caminho duro pela mata escura. $\mathrm{O}$ viajante está velejando, flutuando pelo liso espelho das águas. As embarcações com suas velas brancas são comparadas a borboletas. Os rochedos desnudos "pareciam flutuar no espaço" (ESCHWEGE, 1996, p. 57); "Ao longe, no fundo da baía, ilhas verdejantes e rochedos desnudos que parecem flutuar no ar em função da refração da luz do sol e dos vapores subindo ..." (ESCHWEGE, 1996, p. 57) Aqui o texto assume um registro científico pois ao invés de descrever a imagem poética, explica o fenômeno pelas leis da física. O segundo parágrafo é uma ilustração da percepção do espaço através do movimento, que modifica a perspectiva a cada minuto. Não só a vista muda pelo aumento da distância, também os sons se perdem cada vez mais. Assim se realiza a experiência do espaço, essa mera forma de intuição (Anschauungsform), na sua tridimensionalidade: 'Cada minuto oferece outra vista dos objetos. ... Conventos, igrejas, navios, morros aparecem diminuídos em uma perspectiva mais bela ....' (ESCHWEGE, 1996, p. 57). O texto destaca a percepção estética no seu duplo sentido: do sensorial e do belo. 


\title{
7. Negros e brancos
}

Enquanto os paradoxos surgem nos textos de forma natural, mais por falta de compreensão de um mundo diferente do que por habilidade poética, a ironia é uma marca do seu estilo. Surge também de forma natural do olhar crítico e da postura as vezes arrogante do viajante. Já vimos no texto do Primeiro dia como Eschwege naturalizou o negro na sua posição e função social. Depois de duas décadas, ele interfere no debate sobre a abolição da escravidão e resume, com sarcasmo, sua experiência

\begin{abstract}
Até agora o escravo, [sic] tem sido pau para toda obra: lavrador, fabricante de açúcar e de aguardente, animal de transporte, máquina de britagem e de pulverização, cozinheiro, pajem, palafreneiro, sapateiro, alfaiate, correio e carregador.

É o único bem do homem livre, a cujas necessidades ele provê. Sem seu auxílio, o branco poderia considerar-se pobre, mesmo que suas arcas regurgitassem de ouro. Com efeito, as terras permaneceriam incultas e a mineração desapareceria, caso não existisse o escravo que fizesse todos esses serviços. É ele quem cuida da própria alimentação do senhor, que, se assim não fosse, teria de viver miseravelmente, ou de emigrar para outras terras, onde seu ouro tivesse alguma serventia. (ESCHWEGE, 1979a, p. 263)
\end{abstract}

O paradoxal e a ironia, apenas tímida e vagamente presente no Primeiro dia, aqui são articulados com mais evidência, principalmente a figura do ouro preto, metáfora subentendida para lembrar que o ouro só vale, só brilha por mediação do preto. Não há branco sem preto; o colonizador é seu próprio colonizado.

Quando passa perto da fazenda do Quilombo, abre-se uma pequena janela para a história entrar no texto descritivo da topografia e geologia. Entre a descrição do sertão triste e as rochas regionais, aparece o Quilombo como referência aos negros fugitivos. É a ironia da história, da natureza ou da humanidade que o discurso aqui constrói. Os negros escravos fugiram para os belos campos de sertões de onde até as feras fugiram. Completando a intertextualização que o texto sugere, relacionando os escravos fugitivos ao texto de Humboldt, citado poucas linhas antes, os negros escravos fugiram desse "recanto, ... alheio ao destino da humanidade... que é a própria selva" (ESCHWEGE, 1996, p. 103). Não sabemos se o inconsciente sugeriu que o destino dos negros escravos fosse alheio ao destino da humanidade, livrando-se assim de um complexo moral recalcado.

\section{8. "Luz clara do sol"}

No final do Brasil, Novo Mundo 2, portanto no final dos seus relatos de viagens sobre o Brasil, Eschwege inclui "Algumas notícias sobre as nações indígenas do sul do 
Brasil”. Sob o pretexto de descrever diferenças dos índios no sul e nas províncias do norte do Brasil, o texto articula uma reflexão sobre origem, civilização, cultura e um ser superior textualizada através da oposição simbólica entre "luz clara do sol", associada ao céu e aos campos abertos e a escuridão das "montanhas sombrias e matas impenetráveis." (ESCHWEGE, 2001, p. 151) O olhar do viajante transforma-se em olhar reflexivo, alimentado pelo saber da experiência: "Sei por experiência própria, de quando vivi durante meses na escuridão da mata, como parecia diferente a meus olhos o movimento dos homens vistos de longe." (151)

Contudo, o olhar transcende os fenômenos e abre-se para a memória, a magia, a fantasia e a alma, alma do viajante e dos homens da mata. Nesse olhar transcendental o narrador viaja pela história do homem, refletindo sobre "uma origem mais elevada" (151), pretensões a uma "cultura mais elevada" (151) e "sentimentos de um ser superior" (152), compondo um discurso crítico da civilização. Na medida em que os olhares fenomenal e transcendental se misturam, o texto generaliza suas reflexões e não visa apenas as nações indígenas do sul e do norte do Brasil, mas todos os homens de mentalidade sombria ou clara. A luz clara do sol, que é textualizada como "a luz verdadeira" (151), pode ser entendida como a luz iluminista. não é a luz de uma raça branca em oposição à escuridão de raças de cor. Quando a fantasia do narrador "avistava os homens constrangidos em roupas estreitas... (151), refere-se aos homens presos nas normas da civilização. Quando fala, em seguida, que "não conseguiu descobrir o lado amável e belo da humanidade civilizada" (152), parece contradizer sua crítica anterior. O eco das idéias de Kant da estética transcendental, da experiência, do belo e sublime e da paz eterna estão presentes aqui também.

O texto faz uso freqüente da palavra heiter (claro) que marca a primeira frase do Naturgemälde também, no início do livro. A oposição entre povos da escuridão da mata fechada e povos dos campos livres representa a oposição entre homens guerreiros e homens tranquiilos, projetando uma distinção universal entre os homens para os povos indígenas ou vice versa, utilizando uma distinção entre povos indígenas como simbólica para a humanidade inteira, descrevendo essa distinção carregada de simbologia e saudade de um estado primitivo pacífico da humanidade:

Muito diferentes são os habitantes dos campos, cujo olhar acostumou-se com um horizonte mais aberto e sobre o qual o céu claro atua como benéfica magia, uma magia que produz seus resultados, cobre de verde os campos e lhe desperta no peito o sentimento de um ser superior. Em vez de viverem apenas da caça e seguirem com mãos sujas de sangue e mentalidade sanguinária as trilhas fugidias da caça, acabam por se tornar tranqüilos povos pastores e, como antes, o sangue, passa a ser o leite o alimento dos povos". (ESCHWEGE, 2001, p. 152) 


\section{Conclusões}

\section{Eschwege no Brasil}

Notamos em Eschwege o nascimento da sua escrita articulada por ele mesmo, sua falta de formação cientifica e poética. Manifesta-se o que podemos chamar um Schreibtrieb compensatório, um impulso de escrever para afirmar-se como homem e cientista, mas também em função do mecanismo epistemológico da época que exigiu a busca do conhecimento e a sua fixação. Essa gênese confere certa autenticidade à escrita do viajante. Em termos epistemológicos e epistémicos, utilizando o conceito de Foucault, os viajantes e seus relatos se situam em uma fase de transição da episteme clássica para a moderna, uma fase é marcada pelo criticismo kantiano. A relativa novidade do conceito kantiano de espaço e tempo, como formas a priori da intuição, faz com que Eschwege procura uma definição de espaço em termos de movimento e tempo, na descrição da baia de Guanabara.

Eschwege se revela como viajante híbrido, transcultural, vivendo nos entre lugares, atravessando fronteiras nacionais, naturais, culturais, linhas de guerra e rios divisórias como quando conta das dificuldade de executar uma missão de delimitação de fronteira entre Minas e Goiás, no hoje, Triângulo Mineiro. Passa a fronteira linguiística quando expressa sua saudade utilizando-se da tradução transcultural quando usa a palavra de "saudade" no original alemão. Foi colonizador e colonizado ao mesmo tempo. Serviu a um governo colonizador que de repente viu-se transferido para sua própria colônia por uma potência colonizador maior e então precisou de técnicos para fazer a nova casa habitável. Muito do discurso de Eschwege situa-se no entre lugar do descolonizador, com direito a criticar os ministros que se reservaram o direito de ignorá-lo. Os viajantes ficam descolonizados em outro sentido também, conscientizados da sua função de colonizadores e procurando dando se conta disso.

\section{Brasil em Eschwege}

Adotar a visão desfamiliarizada dos estrangeiros tem vantagens, mas tem um preço também. Segundo S.B. de Holanda, implantou-se no Brasil um sistema cultural cujas origens encontram-se fora dele, na Europa. Trata-se de uma cultura própria de terras estranhas, uma cultura estrangeira, não familiar. Antonio Candido argumenta no mesmo sentido: "Este é um fato por assim dizer natural, dada a nossa situação de povos colonizados que, ou descendem do colonizador, ou sofrem a imposição de sua civilização; mas fato que se complica em aspectos positivos e negativos." (CANDIDO, 1989, p. 148) J. C. Reis observa que as reflexões críticas sobre a identidade cultural brasileira articulam-se nas "interpretações que constituem a corrente do "redescobrimento do Brasil" (1900 a 196070)." (REIS, 2000, p. 17) que procurou rever a historiografia tradicional sob influência franco-alemã. 
Reis lembra que Holanda começa Raízes do Brasil constatando o grande obstáculo para a construção de uma identidade e projeto brasileiros: a representação não se refere à realidade. Lembra, também, que a realidade sempre se apresenta em discursos: Quando se discutem as identidades nacionais do Brasil, tem-se "discursos",
"representações"... Seria possível produzir um discurso sobre o Brasil
desapaixonado, científico, verdadeiro? Dificilmente. É por isso que todas as
representações do Brasil são relevantes, pois, juntas, revelam uma idéia do Brasil
complexa, poliédrica; uma idéia composta de idéias, de projetos, um polígono de
múltiplas faces ao mesmo tempo opostas e interligadas em uma mesma
figura.(REIS, 2000a. p. 45-46)

Identificados os discursos, perguntamos como os olhares, transformados em discursos, contribuíram ou interferiram no imaginário brasileiro. No complexo jogo de olhares de um para o outro, perguntamos se e o que os olhares dos nossos viajantes contribuíram ou até que ponto ofuscaram o olhar do brasileiro para si. Em programo póseleitoral um entrevistado afirmou que agora, com Lula como líder orgânico, seria possível o "olhar próprio sobre si". ${ }^{2}$ Se isso for possível, o olhar próprio se opõe ao olhar do outro. Os viajantes são lidos por seu olhar distanciado que registraram informações históricas. Mas é um olhar estrangeiro, não brasileiro. Na interpretação de uma teoria da psicanalítica do colonialismo utópica, a análise do caráter formador do olhar europeu revela o exótico como uma encomenda européia e vê uma relação entre esta encomenda e sua contrapartida, o racismo. Para o brasileiro isso teria levado a um "complexo do paraíso. Paraíso terrestre, democracia racial e gigante adormecido são os estereótipos do imaginário brasileiro até hoje (GHIRALDELO, 2002, p. 111). Marilena Chaui (CHAUI, 2000) mostra como esse imaginário forma um mito fundador, formado ao longo da história.. A base desse mito é a sagração da natureza, da história e do governante, formando a base para uma sociedade autoritária cujos traços ela resume como o princípio liberal que naturaliza as divisões sociais; indistinção entre o público e o privado, enfraquecendo os direitos civis e o respeito para a lei, e fazendo da lei um privilégio dos grandes; imagem da boa sociedade ordeira na qual conflitos e contradições são sinônimo de desordem; a cultura senhorial e estamental que considera a elite como mais nobre ou como nobreza mesmo. Trata-se de um mito, de crenças, de representações, em suma, de discursos. Na formação desses discursos , a literatura dos viajantes tinha, e tem, sua participação.

Apesar do seu pensamento liberal, o olhar crítico de Eschwege registra o paradoxo da lei não aplicável ou a subversão do legal pela lei do mercado. Registra a inversão do valor de honestidade em função da submissão do poder público aos desejos dos subalternos. Registra os males dos senhores e dos portugueses, mas quando generaliza, as suas afirmações não são isentas de racismo. Os índios, o grande outro, são tanto idealizados quanto inferiorizados. Quando observa que teria sido melhor deixá-los em paz observa também que formariam uma nação poderosa se seriam unidos. No caso da escravidão, a razão torna-se razão instrumental colonial. Eschwege não fala do paraíso. Seu discurso sugere que o estado paradisíaco transforma-se em seu contrário com a intervenção do

2 Marcelo Machado dos Anjos, NETv, Belo Horizonte, canal 15, 06/11/2002, 18hrs. 
homem. Não fala disso de forma abstrata ou doutrinário. Sempre fala a partir do seu olhar quando fala do ouro, dos índios e dos negros no Brasil e em que deu a ação do colonizador europeu sobre eles. Talvez seja uma versão mais concreta do paraíso perdido. Como homem da época da luz e do otimismo iluminista, inicia o segundo volume do seu primeiro livro sobre o Brasil com uma alegoria sugerida pela vista da Serra do Mar, a do gigante deitado, não adormecido, ao qual um gênio diz: "Levanta-te e domina!".

Se a "Reconquista", como série de relatos sobre o Brasil, assumiu um olhar europeu e se a revisão crítica do imaginário sobre o Brasil mostrou seu caráter discursivo contraditório, o discurso pós-colonial questiona o próprio processo da formação desse imaginário, a sua epistemologia, na busca de um olhar próprio de si, mesmo que, por exemplo, nas palavras de A. Moreiras, a apropriação latino-americanista, através do olhar latino americanista, é complexa (MOREIRAS, 2001, p. 160). A dessimetria na produção de conhecimento ainda prevalece na forma de limitações epistémicas historicamente condicionadas. "Pode-se entender que esse estado de coisas representa uma crise indesejada na epistemologia ocidental ...." (MOREIRAS, 2001, p. 162).

Com sua categoria do "pensamento de fora", Foucault propôs uma alternativa a essa epistemologia, enunciando a existência de formas de subjetivação, em contraposição à categoria de sujeito, assumindo uma crítica à qualquer ontologia do sujeito que marcou profundamente a filosofia ocidental desde Descartes. No ensaio sobre as Tecnologias do si, Foucault enuncia a "sua tese central, qual seja, a oposição entre duas modalidades de formas de subjetivação, denominadas respectivamente de cuidado de si e de saber de si. A primeira teria existido na Antiguidade de maneira marcante e a segunda teria se instituído na nossa tradição com o Cristianismo.(BIRMAN, 2000, p. 168)

Supondo um nexo entre "saber de si" e o "olhar próprio para si", perguntamos qual seria o valor dos textos dos nossos viajantes à luz do discurso pós-colonial. Se a alternativa ao acumulo do saber for a volta a um grau zero, Eschwege pode servir como exemplo. Começou com a preocupação que seu papel poderia ficar vazio se os seus pensamentos não ficassem mais ricos e importantes. Se ficaram é uma questão de ponto de vista. Pelos critérios do discurso pós-colonial, seus relatos preenchem os pré-requisitos de um discurso colonial. Seu kantianismo não foi apenas transcendental, mas também moral. Quando observa a inversão do valor da honestidade no trato das coisas públicas em Minas, sua ironia é resultado da irritação com um paradoxo que vai à contramão da sua convicção que para o cidadão, querer e dever (wollen und sollen) devem coincidir para garantir a solidariedade. Mas isso é pensamento de dentro, saber de si. Para Eschwege, um paradoxo ainda era um nó para desenvolver ou resolver; não era puro acontecimento da língua na sua exterioridade. Na distinção de Moreiras, entre hibridismo selvagem e cultural, Eschwege seria talvez um híbrido intercultural a serviço da colonização portuguesa, vislumbrando a independência do Brasil. É interessante notar como, para a compreensão do seu conceito do hibridismo selvagem, Moreiras recorre a Kant para poder pensar a totalidade e "criar a possibilidade de um conceito crítico do híbrido como objeto teleológico do pensamento em sua tentativa de capturar a totalidade social." (MOREIRAS, 2001, p. 349) 


\section{Referências Bibliográficas}

AUGUSTIN, G. Viagens pelo Novo Mundo. Olhar europeu e interculturalidade na literatura de viagem de Eschwege, Spix e Martius. 2003. 304 f. Tese (Doutorado em Estudos Literários). Faculdade de Letras da Universidade Federal de Minas Gerais. Belo Horizonte.

BHABHA, H. K. O Local da Cultura. Belo Horizonte: Editora UFMG, 1998.

BIRMAN, J. A psicanálise na berlinda? In: BRANCO, G. C.; PORTOCARRERO, V. (Org.). Retratos de Foucault. Rio de Janeiro: NAU Ed., 2000, p. 159-178.

BOGDAL, K.-M. (Hrsg). Neue Literaturtheorien. Opladen: Westdeutscher Verlag, 1997.

BRANCO, G. C.; PORTOCARRERO, V. (Org.). Retratos de Foucault. Rio de Janeiro: NAU Ed., 2000.

CANDIDO, A. A Educação pela Noite \& Outros Ensaios. São Paulo: Ática, 1989. Formação da Literatura brasileira. São Paulo, Livraria Martins Editora, 1959.

CHAUI, M. Brasil. Mito fundador e sociedade autoritária. São Paulo: Editora Fundação Perseu Abramo, 2000.

DORNBUSCH. C. Um Cânone da Literatura Alemã nos Trópicos. 1997. 160 f. Tese (Doutorado em Língua e Literatura Alemã) - Faculdade de Filosofia, Letras e Ciências Humanas da Universidade de São Paulo, São Paulo.

ESCHWEGE, L. W. v. Brasilien die Neue Welt. Erster Theil. Braunschweig: Friedrich Vieweg, 1827.

v. Brasilien die Neue Welt. Zweiter Theil. Braunschweig: Friedrich Vieweg, 1824.

ESCHWEGE, W. C. v. Journal von Brasilien. Erster Heft. Weimar: Handels- und Industrie Verlag, 1818.

1818. (1818a).

v. Journal von Brasilien. Zweiter Heft. Weimar: Handels- und Industrie Verlag,

ESCHWEGE, W. L. v. Brasil, novo mundo. Tradução Domício de Figueiredo Murta. Belo Horizonte: Centro de Estudos Históricos e Culturais. Fundação João Pinheiro, 1996.

v. Brasil, novo mundo. Vol. II. Tradução Myriam Ávila. Belo Horizonte: Fundação João Pinheiro, Centro de Estudos Históricos e Culturais, 2000/2001???.

v. Jornal do Brasil, 1811-1817. Trad. Friedrich E. Renger, Tarcísia L. Ribeiro e Günter Augustin. Belo Horizonte: Fundação João Pinheiro, Centro de Estudos Históricos e Culturais, 2002.

v. Pluto Brasiliensis. Vol. 1. Trad. Domício de Figueiredo Murta. Belo Horizonte: Ed. Itatiaia; São Paulo: Ed. da Universidade de São Paulo, 1979.

v. Pluto Brasiliensis. Vol. 2. Trad. Domício de Figueiredo Murta. Belo Horizonte: Ed. Itatiaia; São Paulo: Ed. da Universidade de São Paulo, 1979a. 
FOUCAULT, M As palavras e as coisas. Trad. S. T. Muchail. 3. ed. São Paulo: Martins Fontes, 1985.

HOLANDA, S. B. de. Visão do paraíso. $3^{\text {a }}$ ed. São Paulo, Nacional, 1977.

KANT, I. Crítica da Razão Pura e outros textos filosóficos. São Paulo: Abril, 1974

Kants Werke. Berlin: Walter de Gruyter \& Co., 1968.

LEITE, I. B. Antropologia da Viagem. Belo Horizonte: Editora UFMG, 1996.

LEITE, J. R. T. Viajantes do imaginário: a América vista da Europa, séc. XV-XVII. In: Revista USP. n. 30. Dossiê Brasil dos Viajantes. São Paulo: USP, 1996 a.

LIBBY,D.C. Transformação e trabalho em uma economia escravista: Minas Gerais no século XIX. São Paulo: Brasiliense, 1988.

LINK, J.; PARR, R. Semiotik und Diskursanalyse. In: BOGDAL, K.-M. (Hrsg.). Neue Literaturtheorien. 2. Aufl. Opladen: Westdeutscher Verlag, 1997, p. 108-133.

MOREIRAS, A. A exaustão da diferença. Belo Horizonte: Ed. UFMG, 2001.

NOVAES, A. O Olhar. São Paulo: Companhia das Letras, 1995.

PEIXOTO, N. B. O olhar do estrangeiro. In: Novaes, A. O Olhar. São Paulo: Companhia das Letras, 1995.

PORTOCARRERO, V. Representação e constituição do objeto na modernidade. In: BRANCO, G. C. et al. Retratos de Foucault. Rio de Janeiro: NAU Editora, 2000, p. 29-53.

PRADO, Jr. B. A sombra viva das letras. FOLHA DE SÃO PAULO Mais! n..630, p. 11-12, $14 / 03 / 2004$.

PRATT, M. L. Imperial Eyes. London: Routledge, 1992.

REIS, J. C. Duas versões sobre a formação do Brasil-Nação. In: REVISTA do Legislativo. N. 27 - jan/março de 2000. Edição especial. Repensando o Brasil 500 anos depois. Belo Horizonte, 2000 (2000a).

REIS, J. C. Identidades do Brasil: de Varnhagen a FHC. $3^{\mathrm{a}}$ ed. - Rio de Janeiro : Editora FCV, 2000.

SAID, E. W. Culture and Imperialism. New York: Alfred A. Knopf, 1993.

Orientalism. London:Penguin Books, 1979.

SPURR, D. The Rhetoric of Empire. Colonial Discourses in Journalism, Travel Writing, and Imperial Administration. Durham: Duke University Press, 1993.

\footnotetext{
Abstract: Travel writing textualizes the crossing of geographic as well as intercultural and interdisciplinary frontiers. It represents different and detached perspectives which contribute to cultural memory and imagery. The most recent candidate to enter the canonical list of this type of literature is W. L. v. Eschwege. The analysis of his texts presented in this paper takes a look at the interdisciplinary, intercultural and borderline aspects of his European perspective in transformation while travelling. Postcolonial discourse questions this perspective and its
} 
epistemological implications. The dialectics between strangers' and proper perspective of oneself is at stake.

Keywords: Travel literature; intercultural; european perspective; discourse; Eschwege. 